\title{
Biofertilizers regulate the soil microbial community and enhance Panax ginseng yields
}

\author{
Linlin Dong ${ }^{1}$, Yong $\mathrm{Li}^{2}$, Jiang Xu${ }^{1}$, Juan Yang ${ }^{1}$, Guangfei Wei ${ }^{1}$, Liang Shen ${ }^{1}$, Wanlong Ding ${ }^{2}$ and Shilin Chen ${ }^{{ }^{*}}$
}

\begin{abstract}
Background: Panax ginseng is widely used as functional food and traditional Chinese medicine. To satisfy the market supply and medication safety, biofertilizers are used as agents to stimulate the growth and production of P. ginseng.

Methods: In this study, we used high-throughput sequencing and quantitative polymerase chain reaction to analyze microbial community in soils treated with biofertilizers during the development stages of $P$. ginseng. Ginsenoside content was detected using high-performance liquid chromatography analysis to evaluate the effects of biofertilizer application.

Results: In this study, the incidence rate of $P$. ginseng root rot significantly declined by $40.3-47.3 \%$ after application of disease-biocontrol biofertilizers. Bacterial diversity showed increasing trends in soils treated with $3.0-4.5 \mathrm{ml} \mathrm{kg}^{-1}$ of disease-biocontrol biofertilizers compared with those in untreated soils. Principal coordinate analysis ordination revealed that bacterial communities were changed by biofertilizers depending on their application concentration. Relative abundance of potentially beneficial bacterial agents, such as Bacillus, Burkholderia, Rhizobium, Streptomyces, and Mycobacterium, significantly increased compared with that in control. Fusarium of low abundance observed in soils treated with biofertilizers compared with that in untreated soils. P. ginseng yield was enhanced by 17.0-19.1\%, and ginsenoside (Rg1 and Rb1) contents were improved after biofertilizer application.

Conclusions: Our results reveal that biofertilizers reduced the incidence rate of root rot, increased bacterial diversity, promoted the relative abundance of potentially beneficial bacterial taxa, decreased the abundance of potentially harmful bacterial agents, and then enhanced the yield and quality of $P$. ginseng.
\end{abstract}

Keywords: Panax ginseng, Biofertilizer, Soil microbial community, Root-rot, High-throughput sequencing

\section{Background}

Panax ginseng is known for its value to human health; it boosts energy, reduces stress, and lowers blood sugar and cholesterol levels $[1,2]$. At present, $P$. ginseng cultivation is performed to satisfy the market demands. The use of fertilizer is an effective strategy to increase the supply of $P$. ginseng. However, the overuse of agrochemicals has resulted in massive ecological degradation, including soil infertility, increased salinity, biodiversity loss, and soilborne diseases [3, 4]. Panax root rot is a severe soil-borne disease that spreads rapidly and causes considerable yield

\footnotetext{
${ }^{*}$ Correspondence: slchen@icmm.ac.cn

${ }^{1}$ Key Laboratory of Beijing for Identification and Safety Evaluation of Chinese Medicine, Institute of Chinese Materia Medica, China Academy of Chinese Medical Sciences, Beijing 100700, China

Full list of author information is available at the end of the article
}

loss $[5,6]$. Fusarium oxysporum is one of the main pathogens of Panax plants [7, 8]. Chemical pesticides are used to control disease, but adsorption of residual pesticides by roots can result in serious health issues [9]. Sustainable $P$. ginseng production requires novel pathways to reduce the occurrence of disease and the application of agrochemicals or pesticides that can pollute the environment. Safety biofertilizers and strategies to control soil-borne diseases are urgently needed for the $P$. ginseng cultivation.

Biofertilizers are regarded as environmentally sustainable and cost-effective alternative to synthetic fertilizers $[10,11]$. Biofertilizers are products that contain living microorganisms or natural compounds from organisms that regulate soil biological properties, improve plant growth, restore soil fertility, and decrease plant diseases 
$[12,13]$. Extensive reports on biofertilizers have revealed their capacity to provide nutrients to plants and consequently enhance crop yield [14, 15]. Most commercialized rhizobacterial products serve as bioinoculants to antagonize plant diseases [16]. To satisfy market demands and medication safety requirements, biofertilizers are used as agents to stimulate the growth and yield of $P$. ginseng by increasing the nutrient supply or inhibiting plant diseases.

Microbes are living soil members that play important roles in soil ecosystem activities that promote nutrient mobilization, plant growth, and yield [17, 18]. Variations in diversity and composition of soil microbial communities disrupt the ecological function and negatively affect soil productivity, thereby leading to yield loss [19]. Regulation of soil microbial communities by inoculating functional microbes can renovate microecology and improve crop yield [20,21]. Microorganisms also serve as antagonists to soil-borne phytopathogens. Inoculation of Bacillus subtilis 50-1, for example, alleviates the replanting mortality of $P$. ginseng [8]. P. ginseng, a perennial plant undergoing different developmental stages annually, is continuously cultivated for $4-5$ years prior to harvest. While significant shifts in the diversity of soil microbial communities have been observed during the developmental stages of this plant [8]; few reports are available regarding how biofertilizers affect $P$. ginseng yield by regulating soil microbial communities during these stages.

Panax ginseng is a traditional Chinese medicine, and its main active components are ginsenosides, including Rg1, Re, Rb1, Rc, Rf, Rd, and Rb2 [22]. Ginsenoside content is a vital quality index in the market. Zhao et al. [23] reported that B. amyloliquefaciens GB03 inoculation improves metabolite accumulation in Codonopsis pilosula (Franch.). We speculate that application of biofertilizers affects the ginsenoside content of $P$. ginseng. In this study, we analyzed changes in soil microbial communities under biofertilizer treatment through high-throughput sequencing analysis of 16S RNA genes during the different developmental stages of $P$. ginseng. To evaluate the effects of biofertilizers on potentially harmful taxa, we examined the abundance of Fusarium through quantitative polymerase chain reaction (qPCR). Ginsenoside content was detected using high-performance liquid chromatography to evaluate the effects of biofertilizer application. Our results indicated that biofertilizer application could contribute to the sustainable cultivation and the safe medical use of $P$. ginseng.

\section{Materials and methods}

\section{Site description and field experiment design}

A field experiment was performed in a $P$. ginseng plantation in Jingyu, Jilin Province $\left(42^{\circ} 20 \mathrm{~N}, 126^{\circ} 50^{\prime} \mathrm{E}\right.$,
$775 \mathrm{~m}$ a.s.l.). This experimental site was introduced in the description of Dong et al. [8]. The field area is a traditional farmland with corn, and it has served as a cultivation area of $P$. ginseng since 2014. This area was subdivided in 21 plots with $1.6 \mathrm{~m} \times 6.0 \mathrm{~m}$. The field experiment comprised seven treatments, including treatment with growth-promoting biofertilizers (T1), treatment with disease-biological biofertilizers (T2), and no biofertilizer treatment (CK). The two types of biofertilizers included three concentrations for three treatments. A total of 3.0, 6.0, and $9.0 \mathrm{ml} \mathrm{kg}$ of growth-promoting biofertilizers represented low (T1-L), middle (T1-M), and high (T1-H) concentrations, respectively. Furthermore, $1.5,3.0$, and $4.5 \mathrm{ml} \mathrm{kg}^{-1}$ of disease-biocontrol biofertilizers represented low (T2-L), middle (T2-M), and high (T2-H) concentrations, respectively. T1 of $P$. ginseng comprised a liquid gel suspension containing a phototrophic and N-fixing bacteria consort (Burkholderia and Rhizobium) cultured in vitro. The gel contained over 8000 propagules per milliliter. T2 of $P$. ginseng contained a liquid gel suspension with Gram-positive actinomycetes (Actinomyces), Bacillus and Aspergillus. The gel comprised over 10,000 propagules per milliliter. Different biofertilizer concentrations with organic fertilizer were uniformly mixed and fermented for 30 days with polyethylene film. The main component of the organic fertilizer was pig and cow manure (W/W=1:2), which was provided by Shengshi Baicao, China. Each biofertilizer concentration with organic fertilizers $\left(3.0 \mathrm{~kg} \mathrm{~m}^{-2}\right)$ was randomly applied to one plot as one treatment. Moreover, the application of organic fertilizers without biofertilizers served as the control. This experiment was carried out in triplicate. After 1 month of application, 2-year-old ginseng seedlings $(15 \mathrm{~cm} \times 10 \mathrm{~cm})$ were transplanted into each plot $(1.6 \mathrm{~m} \times 6.0 \mathrm{~m})$ in 2014 . P. ginseng was cultivated according to the standard operating procedures of good agricultural practice $[24,25]$. $P$. ginseng seedlings are commonly cultivated for $4-5$ years before harvest, and they undergo the different developmental stages of vegetative, flower, fruit, and root growth after transplantation. To determine the effectiveness of the biofertilizers applied, we analyzed the growth and soil microbial community during the different developmental stages of $P$. ginseng and assessed the yield and quality of 4-year-old seedlings in 2016.

\section{The incidence rate of $P$. ginseng root rot}

Root rot is a serious $P$. ginseng disease that occurs from June to August each year. P. ginseng root rot was investigated from June to August, and the incidence rate was calculated in August 2015 and 2016 after transplantation. The incidence rate was calculated as the number of diseased plants divided by the number of all plants in each 
plot $(1.6 \mathrm{~m} \times 6.0 \mathrm{~m})$. This experiment was carried out in triplicate.

\section{Soil microbial communities}

To analyze changes in the soil microbial community under biofertilizer treatment, we collected soil samples from different developmental stages of $P$. ginseng seedlings. The sampling times of the developmental stages of vegetative, flower, fruit, and root growth corresponded to the description of Dong et al. [8]. Soil samples were collected from five spots $(0-20 \mathrm{~cm})$ around each seedling root by the drilling method. Soil samples from six seedlings randomly selected from each plot were pooled into one sample. Three replicate were prepared. All samples were homogenized by passing through a $2 \mathrm{~mm}$ sieve for analysis of soil microbial communities. Total soil DNA was extracted using a MoBio Powersoil Kit (MoBio Laboratories Inc., Carlsbad, CA) in accordance with the usage guidelines. DNA samples were stored at $-20{ }^{\circ} \mathrm{C}$ for further processing. Fragments of $16 \mathrm{~S}$ rRNA genes were amplified using the primers 27F/338R [26]. These primers were with an 8 bp pair barcode to analyze the soil microbial communities (Additional file 1: Table S1). Amplification, purification, and quantitation were performed according to the description of Rodrigues et al. [27]. The pooled DNA products were used to construct an Illumina pair-end library and subsequently pair-end sequenced $(2 \times 250)$ on an Illumina HiSeq platform based on standard protocols.

Data were quality filtered using QIIME according to the standard pipeline [28]. Operational taxonomic units (OTUs) were clustered using a 97\% similarity cut-off via UPARSE version 7.1 (http://drive5.com/uparse/). Chimeric sequences were identified using UCHIME. The phylogenetic affiliation of $16 \mathrm{~S}$ rRNA gene sequences was analyzed by the Ribosomal Database Project [29]. Rarefaction analysis according to Mothur v.1.21.1 was performed to determine the diversity indices, including $\mathrm{ACE}$, Chao 1, and Shannon diversity indices. The taxa obtained from RDP Classifier through complete linkage hierarchies were clustered using $R$ package HCLUST (http://sekhon.berkeley.edu/stats/html/hclus t.html). Principal coordinate analysis (PCoA) analysis was performed to compare groups of samples according to Bray-Curtis distance metrics. All data from highthroughput sequencing were submitted to the National Center for Biotechnology Information (http://www.nvbi. nlm.nih.gov), and the accession number of the 16S rRNA sequences was SRP131253.

To evaluate the effects of biofertilizers on potential pathogenic agents, we analyzed the abundance of Fusarium by quantitative PCR analysis. Fusarium fragments were amplified using the primers ITS-Fu-F/ITS-Fu-R
[30]. The copy numbers of Fusarium in soils of $P$. ginseng seedlings among the different treatments were calculated according to the previous description $[8,31]$.

\section{The root growth and yield of $P$. ginseng}

To evaluate the effects of biofertilizers, the fresh root weight and yield of 4-year-old $P$. ginseng seedlings were analyzed in October 2016. A total of 30 plants were used to analyze root growth [32]. Ten $P$. ginseng seedlings were randomly collected from each plot to analyze fresh root weight. $P$. ginseng seedling roots randomly collected from $1 \mathrm{~m}^{2}$ of each plot under different treatments were dried to calculate yields [33]. Data reflect the mean of triplicates.

\section{Ginsenoside contents in $P$. ginseng root}

The standard ginsenosides, namely, Rg1, Re, Rb1, Rb2, Rc, and Rd, were purchased from Shanghai Tauto Biotech Company (Shanghai, China). The standard solutions were dissolved in methanol (Fair Lawn, NJ, USA) for further experiments. Ten samples of $P$. ginseng roots (4-year-old) from each plot were pooled and considered one sample. $P$. ginseng extract preparation was performed according to the description of Dong et al. [22]. Ginsenoside contents were determined through high-performance liquid chromatography (Agilent 1260, USA) using a system equipped with a binary pump, an online degasser, a column compartment, and an auto plate sampler. The reA C18 reversed phase column $(250 \mathrm{~mm} \times 4.6 \mathrm{~mm}$, i.d. $5 \mu \mathrm{m}$; Eclipse XDB, Agilent, USA) was used for separation. The column temperature was kept at $25^{\circ} \mathrm{C}$, and the flow rate and wavelength were $1.0 \mathrm{ml} \mathrm{min}{ }^{-1}$ and $203 \mathrm{~nm}$, respectively. The gradient was composed of water and acetonitrile. The linear gradient was set as follows: 0-12 min for $19 \%$ acetonitrile and $12-60 \mathrm{~min}$ for $19-40 \%$ acetonitrile.

\section{Statistical analysis}

Variables were used to analyze replicates and subjected to ANOVA using SPSS version 16.0 software (SPSS Inc., Chicago, IL, USA). The data were presented as mean \pm SD of $n=3$. No adjustments were implemented for multiple comparisons. Duncan's multiple range test was used to analyze differences between means at a significance level of $P<0.05$.

The Minimum Standards of Reporting Checklist (Additional file 2) contains details of the experimental design, and statistics, and resources used in this study.

\section{Results}

The incidence rate of root rot decreased after application of disease-biocontrol biofertilizers

The chemical properties $(\mathrm{pH}$, total $\mathrm{N}$, organic content, available $\mathrm{P}$ and available $\mathrm{K}$ ) of soils treated with biofertilizers showed insignificant differences compared with 
those of untreated soils before $P$. ginseng cultivation in 2015 (Additional file 1: Table S2). Insignificant differences in emergence rate and the aboveground growth of $P$. ginseng seedlings were also observed in treatments with biofertilizers compared with those in CK (Additional file 1: Figure S1 and Table S3). Root rot infection caused discoloration in $P$. ginseng roots and withered aboveground parts (Fig. 1a). The biocontrol effects of T1 on root rot were insignificant compared with those without biofertilizers in 2015 and 2016 (Fig. 1b, c). The influence of $\mathrm{T} 1$ on damping-off was insignificant compared with those treatments without biofertilizers in 2015 and 2016 (Additional file 1: Figure S2). The incidence rates of root rot and damping-off significantly decreased by 40.3-47.3\% and $30.0-39.4 \%$ in T2 compared with those in CK in 2015 (Fig. 1b and Additional file 1: Figure S2). The biocontrol effect of $\mathrm{T} 2$ on root rot and damping-off were insignificant compared with those of soils without biofertilizers in 2016 (Fig. 1c and Additional file 1: Figure S2).

\section{Biofertilizers changed the diversity of the soil microbial community}

To assess the effects of biofertilizers on soil microecology, we analyzed changes in the soil microbial community in the different developmental stages of $P$. ginseng after biofertilizers were applied for 1 year. A total of 6,328,913 classifiable 16S rRNA sequences and 233,542 OTUs were acquired from 84 soil samples for analysis (Additional file 1: Table S1). The mean numbers of sequences and OTUs per sample were 75,344 and 2780 , respectively. The OTUs ranged from 2394 to 3122 . Compared with that without biofertilizers, the effects of biofertilizers on the bacterial diversity indexes (ACE, Chao, and Shannon) depended on their concentration during the different growth stages of $P$. ginseng seedlings (Table 1 ). Bacterial diversity indices showed increasing trends in T1-M soils $\left(6.0 \mathrm{ml} \mathrm{kg}^{-1}\right)$ from the vegetative stage to the root growth stage of $P$. ginseng compared with those in untreated soils (CK). Diversity indices also displayed higher values in $\mathrm{T} 2-\mathrm{M}$ and $\mathrm{T} 2-\mathrm{H}$ soils ( 3.0 and $4.5 \mathrm{ml} \mathrm{kg}{ }^{-1}$, respectively) than those in untreated soils from the vegetative stage to the root growth stage of $P$. ginseng. In addition, diversity indices were significantly higher in T2-M soils during the vegetative and fruiting stages than in untreated soils. These results indicate that biofertilizers change the diversity of the soil microbial community and that the effects of the biofertilizer depended on the application concentration.

\section{Biofertilizers changed the soil microbial community}

PCoA ordination revealed changes in the bacterial communities in T1 and T2 soils compared with that in CK

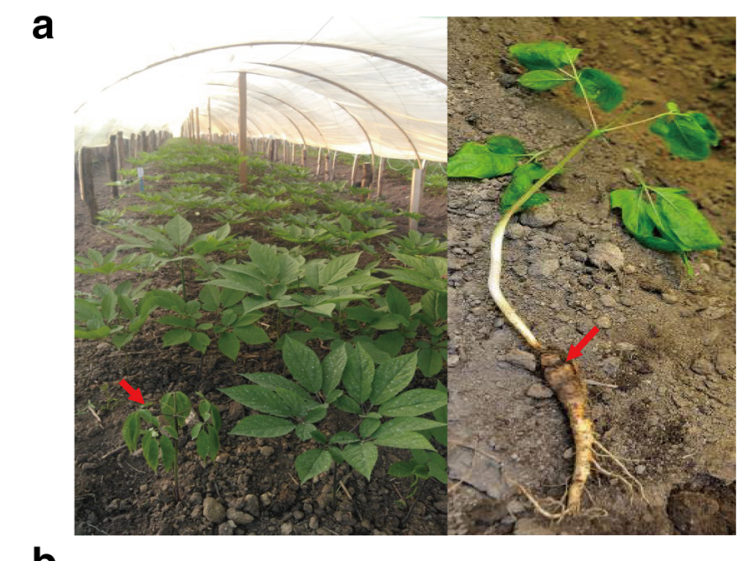

b
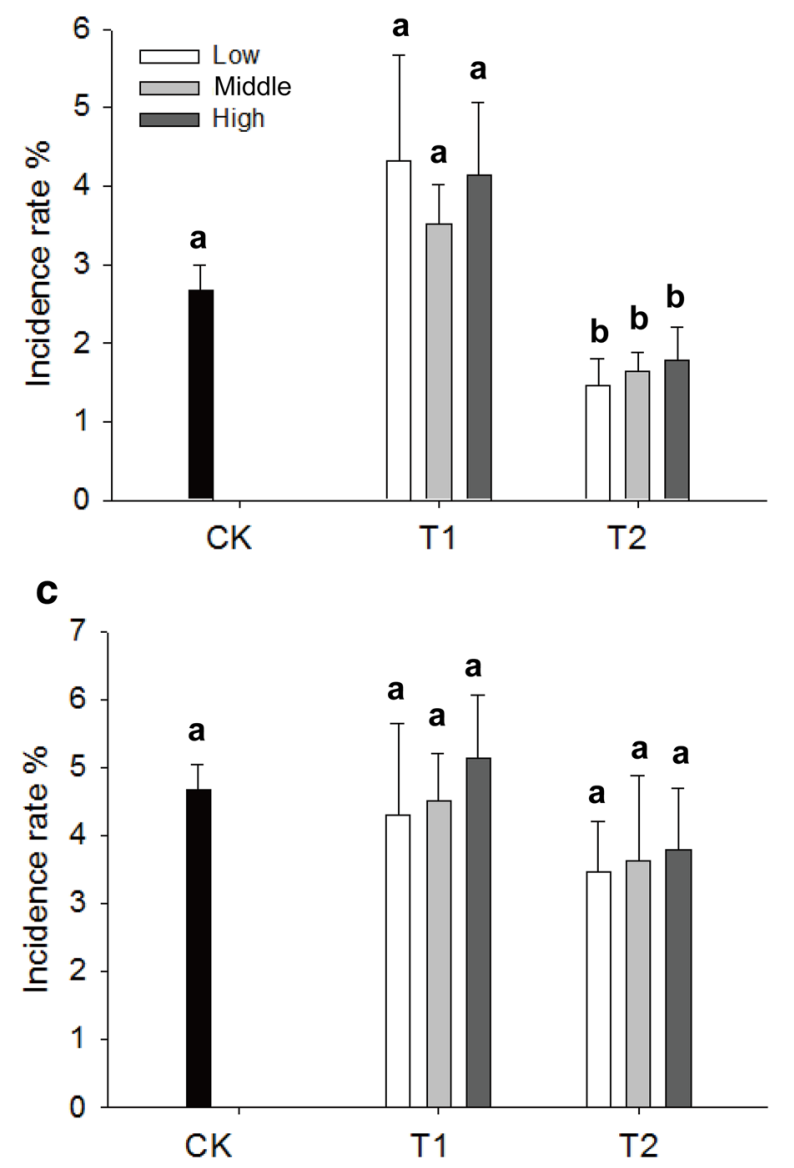

Fig. 1 Incidence rate of Panax ginseng root rot. a Symptoms of root rot. $\mathbf{b}$ Incidence rate of root rot in 2015. c Incidence rate of root rot in 2016. CK represents the treatment without biofertilizers. T1 and T2 represent treatments with growth-promoting and disease-biocontrol biofertilizers, respectively. Data are presented as mean $\pm \mathrm{SD}(n=3)$. Identical letters denote insignificant differences among treatments at the 0.05 level

soils (Fig. 2). During the vegetative stage of $P$. ginseng, the first principal component $(56.20 \%$ contribution) demonstrated bacterial communities in $\mathrm{T} 2-\mathrm{L}, \mathrm{T} 2-\mathrm{M}$, and 


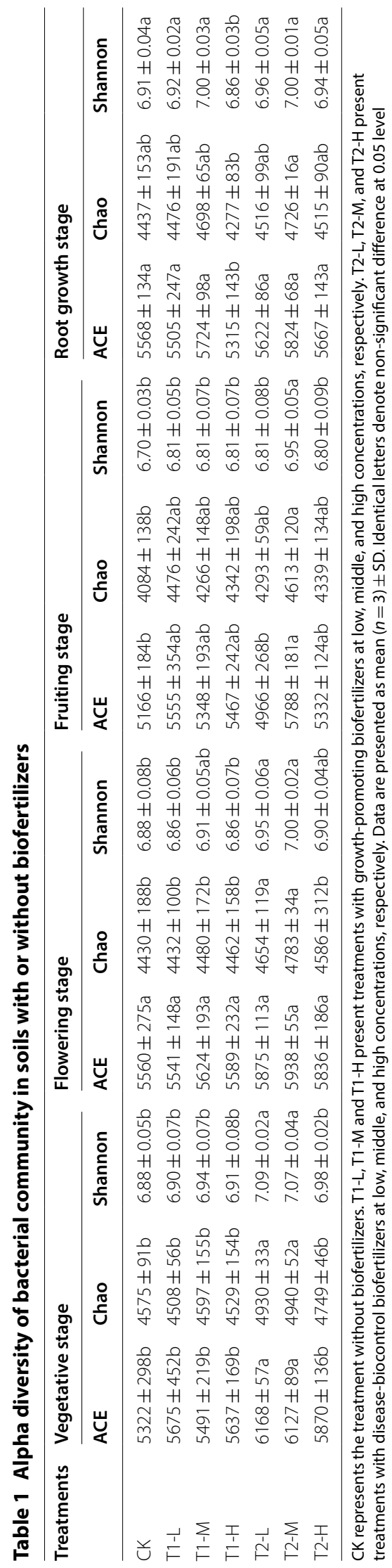



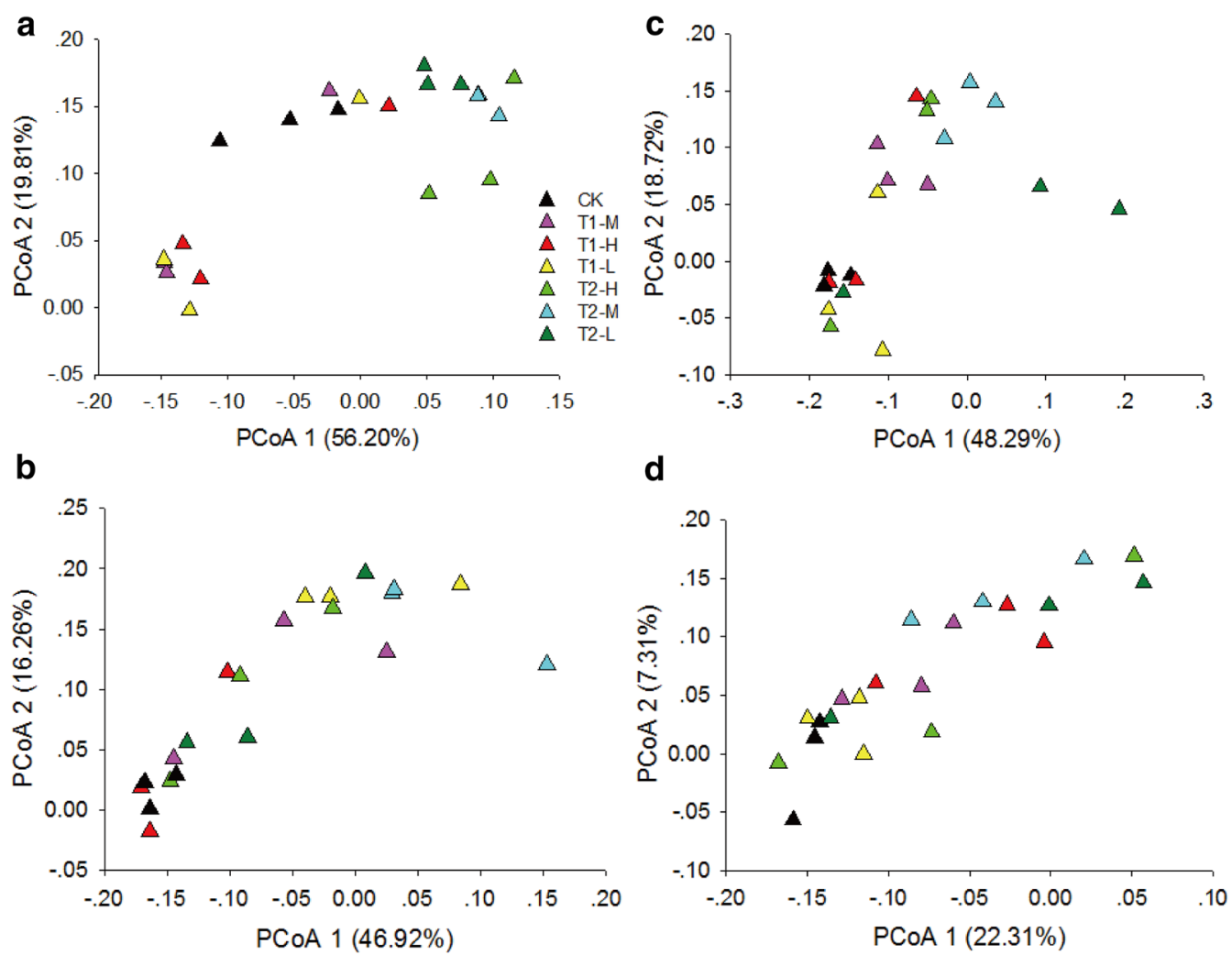

Fig. 2 Changes in bacterial communities in soils with and without biofertilizer. a-d Principal coordinate analysis ordination plots show the relatedness of samples separated using the Bray-Curtis distances of the classified $16 \mathrm{~S}$ rRNA gene sequences at the vegetative, flowering, fruiting, and root growth stages. CK represents the treatment without biofertilizers. T1-L, T1-M, and T1-H represent treatments with growth-promoting biofertilizers at low, middle, and high concentrations, respectively. T2-L, T2-M, and T2-H represent treatments with disease-biocontrol biofertilizers at low, middle, and high concentrations, respectively

T2-H soils compared with those in CK (Fig. 2a). During the flowering stage of $P$. ginseng, the first principal component axis (46.92\% contribution) showed that bacterial communities in T2-M soils markedly differed from those in T1-H, T2-H, and CK soils (Fig. 2b). During the fruiting stage of $P$. ginseng, the second principal component axis (18.72\% contribution) indicated that the bacterial communities in T1-M and T2-M soils differed from those in CK (Fig. 2c). During the root growth stage of P. ginseng, $\mathrm{PCoA}$ ordination showed insignificant differences in bacterial communities between soils treated with biofertilizers and CK (Fig. 2d).

\section{Biofertilizers changed the relative abundance of bacterial groups}

The relative abundance of bacterial groups changed in treated or untreated soils from the phylum level to the genus level during the different developmental stages of P. ginseng (Additional file 1: Figures S3, S4 and Fig. 3). Acidobacteria, Actinobacteria, Chloroflexi, Gemmatimonadetes, Proteobacteria, and Verrucomicrobia were the main bacterial taxa at the phylum level in soils of $P$. ginseng (Additional file 1: Figure S3). During the flowering and fruiting stages of $P$. ginseng, the relative abundance of Gemmatimonadetes showed decreasing trends in T1 and T2 soils compared with those in CK soils.

(See figure on next page.)

Fig. 3 Changes in bacterial genera in soils with and without biofertilizers. a-d Changes in the relative abundance of bacterial genera at the vegetative, flowering, fruiting, and root growth stages. Heat map showing major bacterial genera with average relative abundance $>0.05 \%$ in all samples. Clustering on the $x$-axis relied on the bacterial composition of the samples. CK represents the treatment without biofertilizers. T1-L, T1-M, and $\mathrm{T} 1-\mathrm{H}$ represent treatments with growth-promoting biofertilizers at low, middle, and high concentrations, respectively. T2- $\mathrm{L}, \mathrm{T} 2-\mathrm{M}$, and $\mathrm{T} 2-\mathrm{H}$ represent treatments with disease biocontrol biofertilizers at low, middle, and high concentrations, respectively. Data are presented as mean $(n=3)$ 


\section{a}

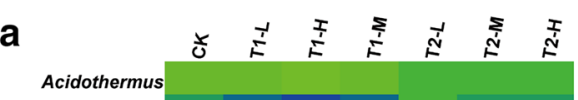

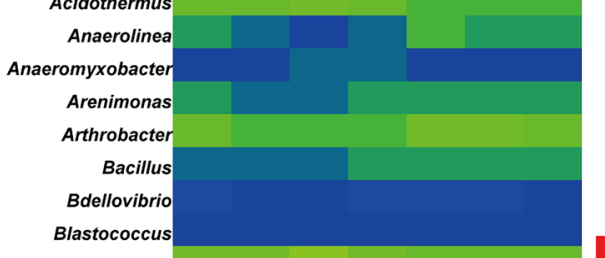

Bradyrhizobium

Burkholderia

Cryobacterium

Flavobacterium

Gemmatimonas

Haliangium

Hyphomicrobium

Janthinobacterium

Lysobacter

Methanobacterium

Mycobacterium

Novosphingobium

Phenylobacterium

Pseudolabrys

Rhizobium

Rhizomicrobium

Sphingomonas

Streptomyces

Variibacter

b

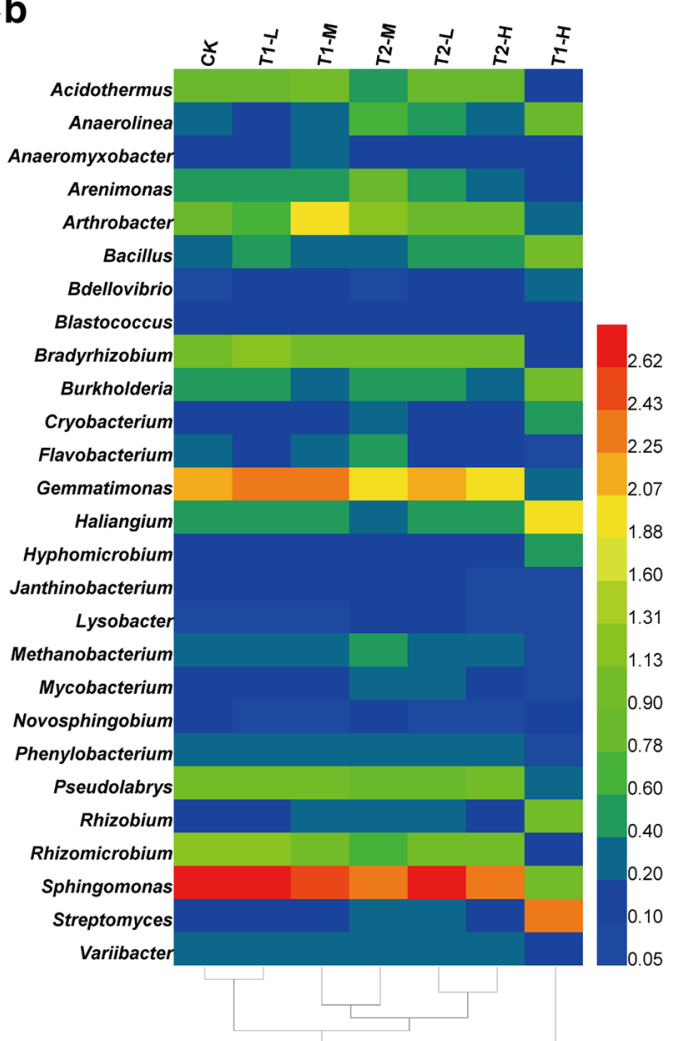

c

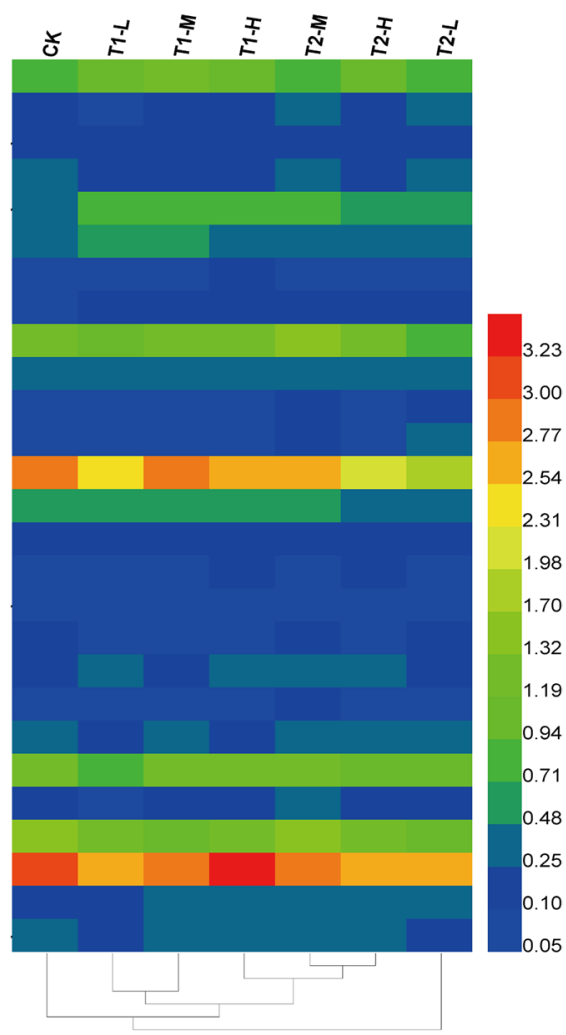

d

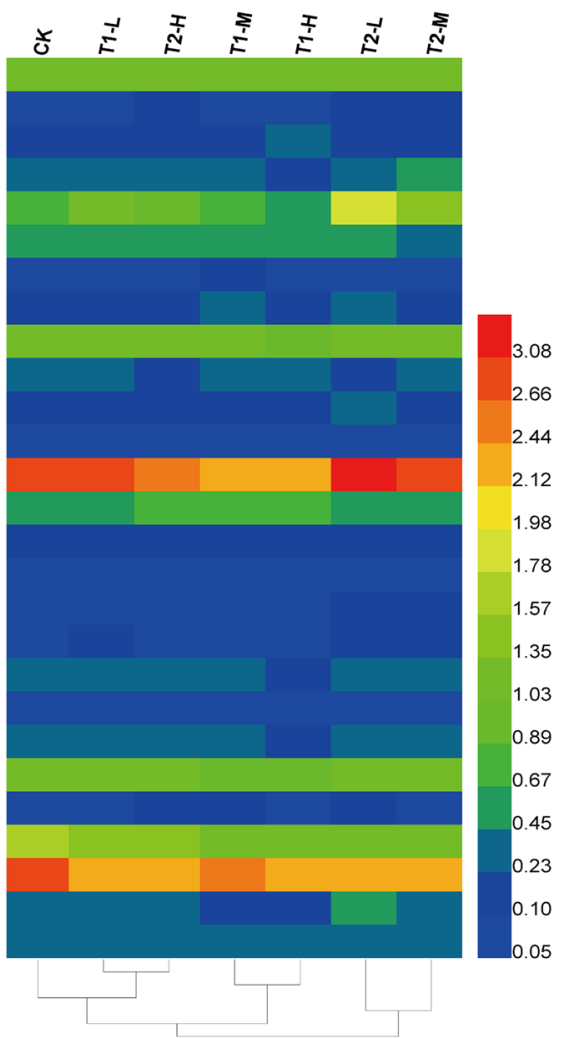


Additionally, Chloroflexi abundance increased in T1 and T2 soils compared with those in CK soils during the flowering, fruiting, and root growth stages of $P$. ginseng. The relative abundance of bacterial groups showed fluctuations at the family level in treated or untreated soils (Additional file 1: Figure S4).

During the vegetative stage of $P$. ginseng, the relative abundances of Anaerolinea, Cryobacterium, and Methanobacterium significantly declined by $54.5-69.5 \%$, $24.8-28.2 \%$, and $48.9-88.5 \%$, respectively, in soils with biofertilizers compared with those in soils without biofertilizers. The relative abundances of Anaeromyxobacter, Bdellovibrio, and Sphingomonas increased by $56.0-82.3 \%, 11.4-65.7 \%$, and $17.6-21.6 \%$, respectively, in T1 soils compared with those in CK soils (Fig. 3a). Moreover, the relative abundance of Bacillus, Flavobacterium, Rhizobium, and Streptomyces increased by $30.3-57.2 \%$, $10.2-82.5 \%, 77.9-116.7 \%$, and $14.9-102.0 \%$, respectively. The relative abundances of Haliangium and Methanobacterium decreased by $10.8-17.1 \%$ and $15.4-33.4 \%$, respectively, in T2 soils compared with those in CK soils.

During the flowering stage of $P$. ginseng, the relative abundances of Arenimonas and Pseudolabrys declined by $12.0-64.0 \%$ and $12.0-78.7 \%$, respectively, in soils with biofertilizers compared with those in soils without biofertilizers. The relative abundance of Bdellovibrio markedly increased by $37.8-303.4 \%$ in T1 soils compared with those in CK soils (Fig. 3b). The relative abundances of Bacillus, Burkholderia, Rhizobium, and Streptomyces significantly increased by $185.7 \%, 121.1 \%, 439.0 \%$, and $116.2 \%$, respectively, in $\mathrm{T} 1-\mathrm{H}$ soils compared with those in CK soils. The relative abundances of Anaerolinea and Rhizobium increased by $17.1-230.0 \%$ and $14.1-125.6 \%$, respectively, in T2 soils compared with those in CK soils. The relative abundances of Mycobacterium and Streptomyces markedly increased by $45.0-57.9 \%$ and $161.6-$ $179.2 \%$, respectively, in T2-L and T2-M soils compared with those in CK soils.

In the fruiting stage of $P$. ginseng, the relative abundances of Mycobacterium and Streptomyces significantly increased by $11.5-140.0 \%$ and $20.3-144.3 \%$, respectively, in $\mathrm{T} 1$ and $\mathrm{T} 2$ soils compared with those in CK soils (Fig. 3c). The relative abundances of Acidothermus and Bacillus increased by $37.0-67.2 \%$ and $13.3-31.9 \%$, respectively, in T1 soils compared with that in CK soils.

In the root growth stage of $P$. ginseng, the relative abundances of Bacillus, Burkholderia, and Rhizobium significantly increased by $28.0 \%, 28.6 \%$, and $45.3 \%$, respectively, in T1-M soils compared with those in CK soils (Fig. 3d). The relative abundances of Anaerolinea, Arthrobacter, Cryobacterium, and Janthinobacterium were remarkably higher in T2 soils than in CK soils. The relative abundances of Bacillus and Rhizobium significantly increased by $34.3 \%$ and $35.3 \%$ in T2-L soils compared with those in CK soils.

\section{Biofertilizers reduced the relative abundance of Fusarium} The relative abundance of Fusarium was reduced in T1 and T2 soils compared with that in CK soils (Fig. 4). The relative abundance of Fusarium decreased by $11.4-18.8 \%$ and $13.1-31.2 \%$ in $\mathrm{T} 1$ (middle concentration) and $\mathrm{T} 2$ (low concentration) soils, respectively, compared with those in CK soils in 2015 (Fig. 4a). The relative abundance of Fusarium declined by $15.9-18.9 \%$ in T1 soils (middle concentration) during the flowering, fruiting, and root growth stages of $P$. ginseng compared with those in untreated soils in 2016 (Fig. 4b). Fusarium abundance significantly decreased in T2 soils during the fruiting and root growth stages of $P$. ginseng compared with those in untreated soils in 2016.

\section{Biofertilizers enhanced the root growth and yield of $P$. ginseng}

The root growth and yield of $P$. ginseng increased depending on the concentrations of biofertilizer application (Fig. 5). While T1-M enhanced the root growth and yield of $P$. ginseng by $16.5 \%$ and $17.0 \%$, respectively, T2-L and T2-M improved the root growth and yield of the plant by $13.5-15.7 \%$ and $18.1-19.1 \%$, respectively.

\section{Biofertilizers improved the ginsenoside content of $P$. ginseng root}

The ginsenoside (Rg1 and Rb1) content in 4-year-old $P$. ginseng roots improved depending on the applied concentration of biofertilizers (Fig. 6). T1-M and T2-M significantly increased $\mathrm{Rg} 1$ and $\mathrm{Rb} 1$ contents, respectively, compared to those without biofertilizers. The field experimental results indicate that biofertilizers improve the quality of $P$. ginseng in a concentration-dependent manner.

\section{Discussion}

The incidence rate of $P$. ginseng root rot significantly decreased by $40.3-47.3 \%$ through $\mathrm{T} 2$ application within 1 year. $P$. ginseng yields and ginsenoside (Rg1 and Rb1) contents were enhanced in $\mathrm{T} 1$ and $\mathrm{T} 2$ in a concentrationdependent manner. Biofertilizers are widely accepted because they promote plant root growth and protect roots from soil-borne pathogens [34]. The results of biofertilizer application may offer information about the development of disease control strategies [35]. Biofertilizers containing B. amyloliquefaciens strain NJN-6 with organic mixtures of pig manure and amino acids can suppress banana Fusarium wilt disease [36]. El-Haddad et al. [37] reported that biofertilizers, including phosphatesolubilizing bacteria, that is, B. circulans, and N-fixing 

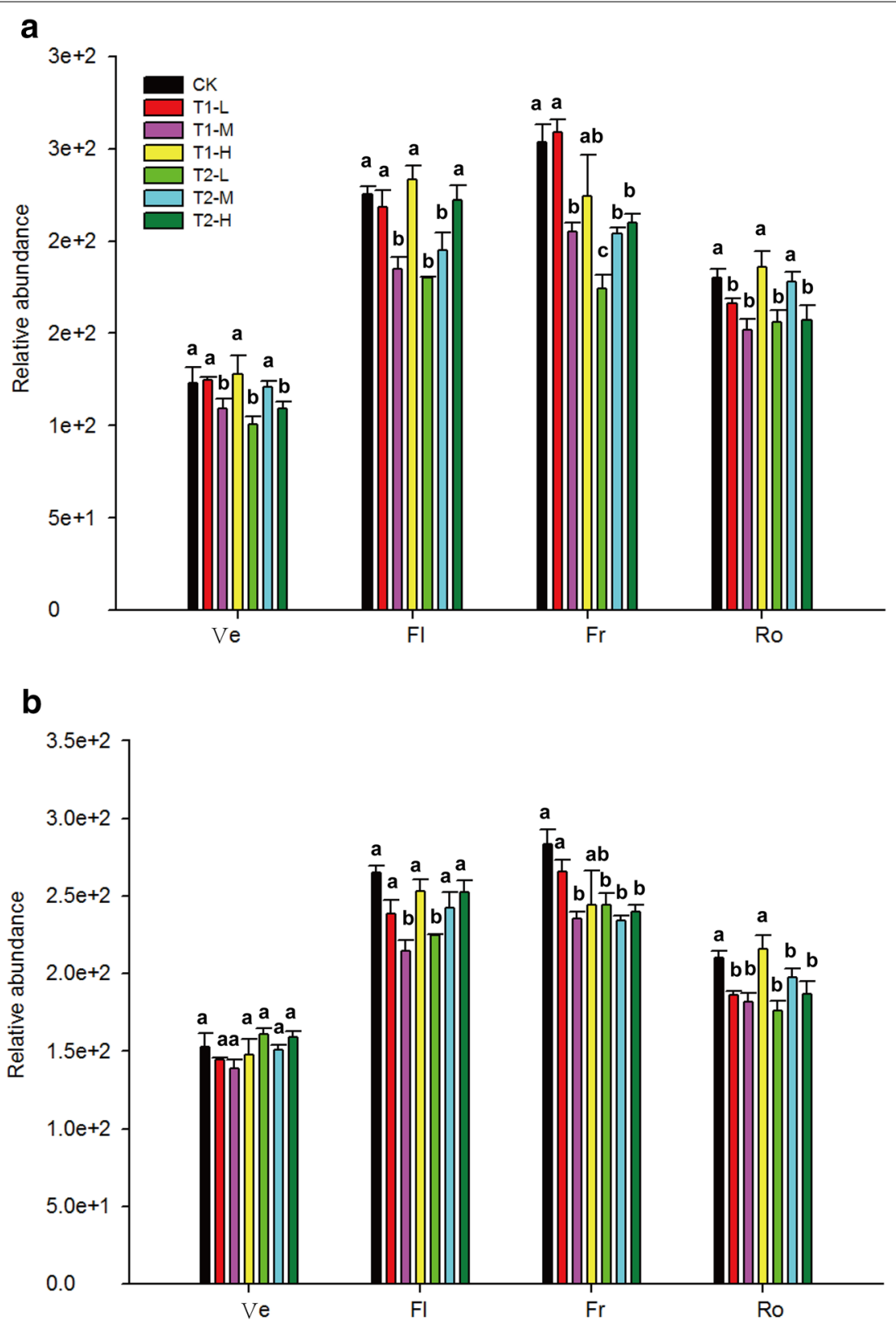

Fig. 4 Changes in the relative abundance of Fusarium in soils with and without biofertilizers during the different developmental stages of $P$. ginseng in 2015 (a) and 2016 (b). Ve, Fl, Fr, and Ro represent the vegetative, flowering, fruiting, and root growth stages, respectively. CK represents the treatment without biofertilizers. T1-L, T1-M, and T1-H represent treatments with growth-promoting biofertilizers at low, middle, and high concentrations, respectively. T2-L, T2-M, and T2-H present treatments with disease-biocontrol biofertilizers at low, middle, and high concentrations, respectively. Data are presented as mean \pm SD $(n=3)$. Identical letters denote insignificant differences among treatments in the same developmental stage at the 0.05 level

bacteria, show significant nematicidal activity. In addition, the incidence rate of $P$. ginseng damping-off significantly decreased by $30.0-39.4 \%$ in T2 within 1 year (Additional file 1: Figure S2). While the incidence rate of $P$. ginseng root rot showed increasing trends in T1, these increases were insignificant. Multiple microbial interactions include antibiosis, competition, and symbiosis [38]. Application of microbial inoculants can influence resident microbial communities and disrupt the ecological balance in soil microbial communities [39]. Inoculation of growth-promoting biofertilizers containing living strains can cause imbalance in the rhizosphere and result 

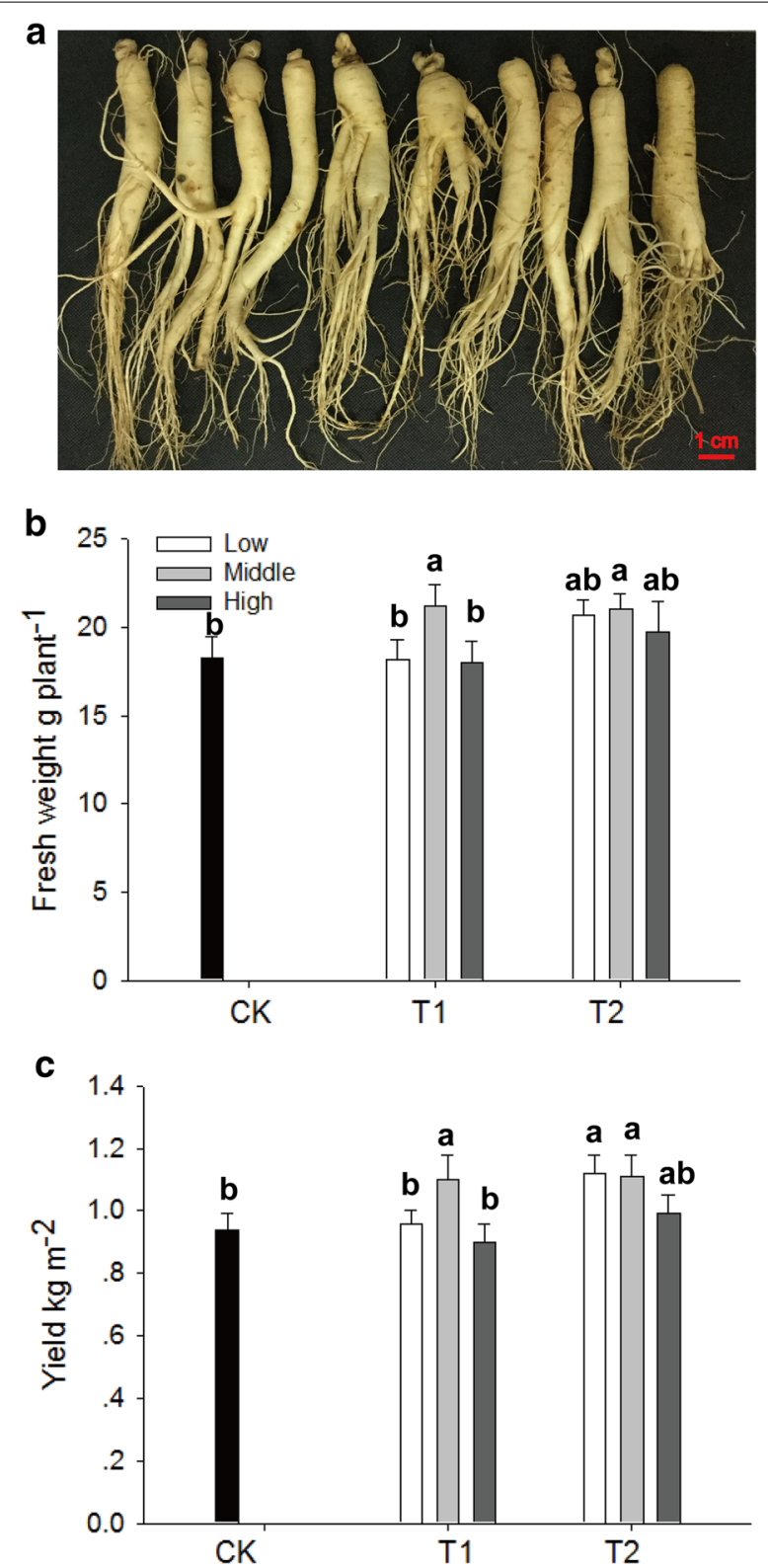

Fig. 5 Root growth and yield of $P$. ginseng. a The 4-year-old $P$. ginseng root. $\mathbf{b}$ Fresh weights of roots in treatments with and without biofertilizers. c Yields in treatments with and without biofertilizers. CK represents the treatment without biofertilizers. T1 and T2 represent treatments with growth-promoting and disease-biocontrol biofertilizers, respectively. Data are presented as mean \pm SD $(n=3)$. Identical letters denote insignificant differences among treatments at the 0.05 level

in the increased incidence rate of root rot. Thus, the biofertilizer type should be considered in practical applications. Bacterial populations enhance yield and serve as antagonists of soil-borne disease [15]. Application of inoculants, such as B. amyloliquefaciens GB03, improves the metabolite accumulation of C. pilosula (Franch.) [23].
Li and Huang have reported that application of biological fertilizer improve the indexes of $P$. ginseng growth and total ginsenosides [40]. The yield of $P$. ginseng is increased by $10-30 \%$ after application of biofertilizers [41]. Similar to the present results, these findings reveal that biofertilizers can enhance the quality of medicinal materials.

Bacterial diversity indexes evidently increased, and the compositions of soil microbial communities changed in $\mathrm{T} 1$ and T2 soils compared with those in CK soils; the effects of biofertilizers depend on their concentrations of application. Biofertilizer application increases the bacterial diversity in soils of cucumber and tobacco [42, 43]. Moreover, biofertilizer application (2 years continuously) regulates the compositions of microbial communities by increasing the bacterial diversity [44]. Dong et al. [45] have reported that biofertilizer application changed the diversity and composition of microbial communities. These results indicated that biofertilizer application manipulated the diversity and compositions of soil microbial communities.

Plant growth-promoting rhizobacteria (PGPR) directly or indirectly play vital roles in plant health and soil fertility [15]. A large number of PGPR genera, including Bacillus, Enterobacter, Burkholderia, Pseudomonas, Rhizobium, Streptomyces, Sphingobacterium, and Mycobacterium, have been characterized [46-48]. Evident strains include Rhizobium, Burkholderia, Pseudomonas, and Bacillus, which can solubilize insoluble inorganic phosphorus [13]. Many types of biofertilizers, such as Enterobacter, Mycobacterium, and Streptomyces, produce IAA, which induces plant stress resistance [49-51]. Several biofertilizers, such as Pseudomonas, produce antifungal antibiotics that can inhibit plant pathological fungi [52]. The abundance of beneficial microbial taxa that can control Fusarium wilt disease, such as Pseudomonas and Bacillus, increased in $\mathrm{T} 1$ and $\mathrm{T} 2$ soils compared with those in CK soils [44]. In the present study, the biofertilizers contained PGPR, such as a phototrophic and $\mathrm{N}$-fixing bacteria consort, Gram-positive actinomycetes, Bacillus and Aspergillus. After biofertilizer application, the relative abundance of potentially beneficial bacterial taxa, such as Bacillus, Burkholderia, Rhizobium, Streptomyces, and Mycobacterium, showed increasing trends. Furthermore, the abundance of Fusarium decreased in $\mathrm{T} 1$ and T2 soils. The direct mechanism of PGPR involves improvements in $\mathrm{N}$ fixation, phosphate solubilization, and phytohormone while its indirect mechanism involves improvements in hydrolytic enzyme production, exopolysaccharide production, and induced system resistance [13]. Taken together, we speculate that application of biofertilizers, including functional groups, promotes $P$. ginseng yield by modifying the soil microecology and inhibiting plant pathogenic diseases (Fig. 7). Several 

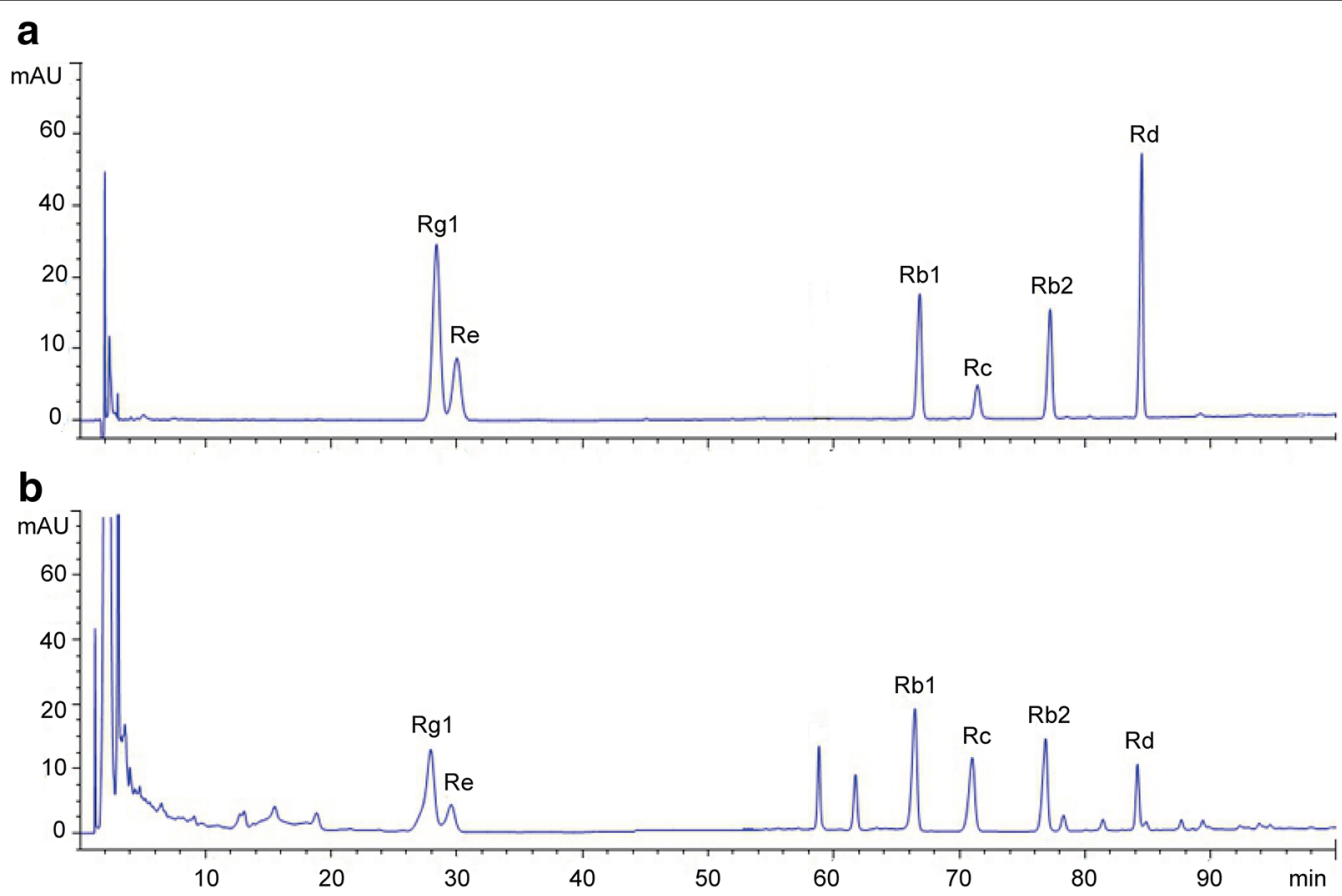

C

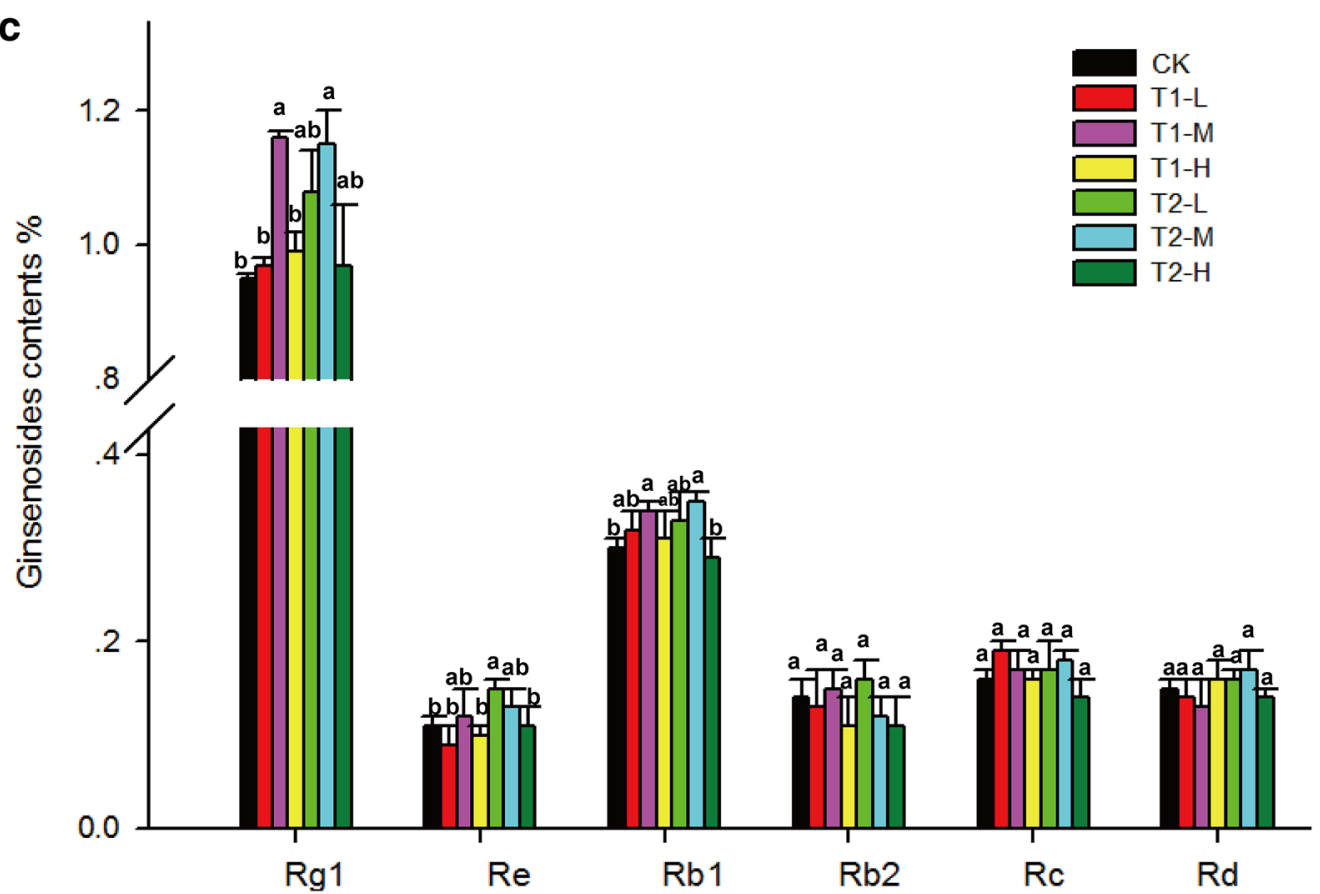

Fig. 6 Ginsenoside contents (\%) of four-year-old P. ginseng roots. a Mixed standards. b HPLC chromatogram profiles of $P$. ginseng roots. c Contents of $\mathrm{Rg} 1, \mathrm{Re}, \mathrm{Rb} 1, \mathrm{Rc}, \mathrm{Rb} 2$, and $\mathrm{Rd}$ in $P$. ginseng roots. CK represents the treatment without biofertilizers. T1-L, T1-M, and T1-H represent treatments with growth-promoting biofertilizers at low, middle, and high concentrations, respectively. T2-L, T2-M, and T2-H represent treatments with disease-biocontrol biofertilizers at low, middle, and high concentrations, respectively. Data are presented as mean $\pm S D(n=3)$. Identical letters denote insignificant differences among treatments at the same developmental stage at the 0.05 level 


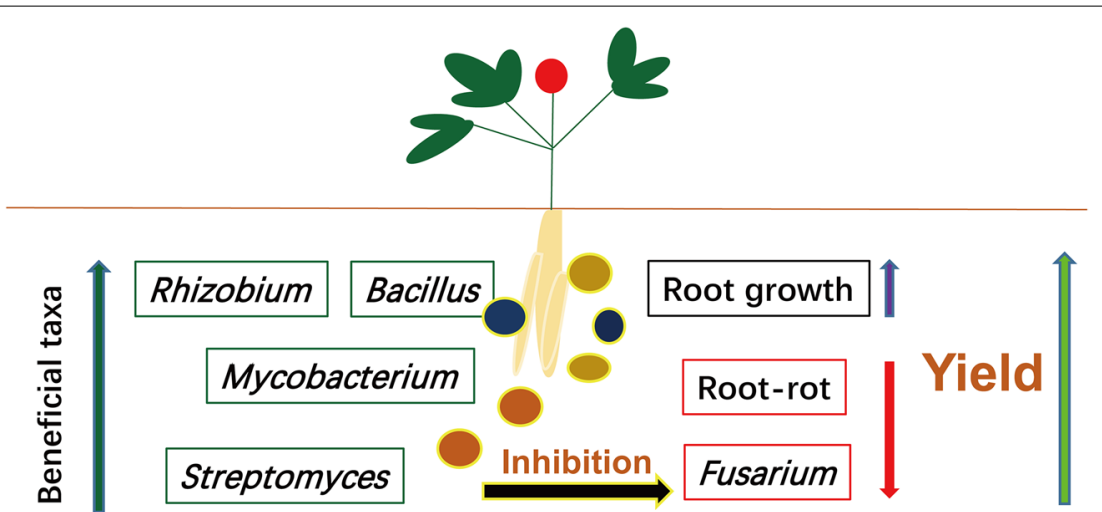

Fig. 7 Potential mechanism of biofertilizers regulating the soil microecology to enhance yield. Circles represent bacterial secretions

beneficial bacterial groups can solubilize phosphate to promote the growth of $P$. ginseng root. In addition, other groups secreting antifungal antibiotics can decrease the risk of soil-borne diseases. Our results provided important information about biofertilizer application and contributed to the safe medical use of $P$. ginseng.

\section{Conclusions}

In this study, biofertilizers reduced the incidence rate of root rot, increased bacterial diversity, promoted the relative abundance of potentially beneficial bacterial taxa, decreased the abundance of potentially harmful bacterial agents, and enhanced the yield and quality of $P$. ginseng. The influence of the biofertilizers depended on their application concentrations. These results provide vital information that can be used as a guide for biofertilizer application and contribute to the sustainable production of $P$. ginseng. This work also offers effective approaches to guarantee the safe medical use of the plant.

\section{Additional files}

Additional file 1: Table S1. Barcodes, OTUs and numbers of bacterial sequences in each sample. Table S2. Soil chemical properties in the soils of $P$. ginseng plants. Table S3. The height and leaf area of $P$. ginseng plants in different treatments. Table S4. Calibration curves, linearity, precision, repeatability, stability and recovery rate of six ginsenosides. Figure S1. The emergence rate of $P$. ginseng plants in 2015 (A) and 2016 (B). Figure S2. Incidence rate of $P$. ginseng damping-off. Figure S3. The relative abundance of bacterial taxa at the level of phylum. Figure S4. Relative abundance $(>0.10 \%)$ of bacterial groups in soils of different treatments during developmental stages of $P$. ginseng.

Additional file 2. Minimum Standards of Reporting Checklist.

\section{Abbreviations}

rRNA: ribosomal RNA; PCR: polymerase chain reaction; PCoA: principal coordinates analysis; RDP: ribosomal database project; OTUs: operational taxonomic units; $H^{\prime}$ : Shannon index; PGPR: plant growth-promoting rhizobacteria.

\section{Acknowledgements}

We thank Jun Qian for analysis of 16S rRNA gene sequences.

\section{Authors' contributions}

SC designed the work and wrote this manuscript. LD designed the work, analyzed the data, and wrote the manuscript. YL and JX analyzed the data. JY and GW performed the experiment. LS and WD collected samples. All authors read and approved the final manuscript.

\section{Funding}

This study was supported by grants from the Beijing Nova Program (No. Z181100006218020), the National Natural Science Foundation of China (No. 81603238), and the Fundamental Research Funds for the Central public welfare research institutes (No. ZXKT17049).

\section{Availability of data and materials}

The 16S rRNA sequences of endophytes used in this manuscript have been submitted to the NCBI and the Accession number is SRP131253. Most of the data generated of analyzed during the study are included in this article and its Additional file 1.

\section{Ethics approval and consent to participate} Not applicable.

\section{Consent to publish}

Not applicable.

\section{Competing interests}

The authors declare that they have no competing interests.

\section{Author details}

${ }^{1}$ Key Laboratory of Beijing for Identification and Safety Evaluation of Chinese Medicine, Institute of Chinese Materia Medica, China Academy of Chinese Medical Sciences, Beijing 100700, China. ${ }^{2}$ Institute of Medicinal Plant Development, Chinese Academy of Medical Sciences \& Peking Union Medical College, Beijing 100193, China.

Received: 11 March 2019 Accepted: 4 May 2019

Published online: 23 May 2019

\section{References}

1. Kim S, Park J. Trends in ginseng research in 2010. J Ginseng Res. 2011;35:389-98.

2. Tran T, Kim Y, Yang J, Oh D, Dao T, Oh W. Dammarane triterpenes from the leaves of Panax ginseng enhance cellular immunity. Bioorg Med Chem. 2014;22:499-504.

3. Savci S. An agricultural pollutant: chemical fertilizer. Int J Environ Sci Dev. 2012;3:77-80. 
4. Hallmann C, Foppen RPB, van Turnhout CAM, de Kroon H, Jongejans E. Declines in insectivorous birds are associated with high neonicotinoid concentrations. Nature. 2014;511:341-3.

5. Darmono TW, Owen ML, Parke JL. Isolation and pathogenicity of Phytophthora cactorum from forest and ginseng gardens in Wisconsin. Plant Dis. 1991;75:610-2.

6. Dong L, Yao H, Li Q, Song J, Li Y, Luo H, Chen S. Investigation and integrated molecular diagnosis of root-knot nematode in Panax notoginseng root in the field. Eur J Plant Pathol. 2013:137:667-75.

7. Dong L, Xu J, Feng G, Li X, Chen S. Soil bacterial and fungal community dynamics in relation to Panax notoginseng death rate in a continuous cropping system. Sci Rep. 2016;6:31802.

8. Dong L, Xu J, Zhang L, Cheng R, Wei G, Su H, Yang J, Qian J, Xu R, Chen S. Rhizospheric microbial communities are driven by Panax ginseng at different growth and biocontrol bacteria alleviated replanting mortality. Acta Pharm Sin B. 2018:8:272-82.

9. Lee BD, Dutta S, Ryu H, Yoo S, Suh D, Park K. Induction of systemic resistance in Panax ginseng against Phytophthora cactorum by native Bacillus amyloliquefaciens HK34. J Ginseng Res. 2015;39:213-20.

10. Zheng Y, Xue QY, Xu LL, Xu Q, Lu S, Gu C. A screening strategy of fungal biocontrol agents towards Verticillium wilt of cotton. Biol Control. 2011;56:209-16.

11. Kawalekar SJ. Role of biofertilizers and biopesticides for sustainable agriculture. J Bio Innov. 2013;2:73-8.

12. Abdel-Raouf N, Al-Homaidan AA, Ibrabeem IBM. Agricultural importance of algae. Afr J Biotechnol. 2012;11:11648-58.

13. Mahanty T, Bhattacharjee S, Goswami M, Bhattacharyya P, Das B, Ghosh A, Tribedi P. Biofertilizers: a potential approach for sustainable agriculture development. Environ Sci Pollut Res Int. 2017;24:3315-35.

14. Sevilla-Perea A, Mingorance MD. Field approach to mining-dump revegetation by application of sewage sludge co-compost and a commercial biofertilizer. J Environ Manag. 2015;158:95-102.

15. Mukhtar S, Shahid I, Mehnaz S, Malik KA. Assessment of two carrier materials for phosphate solubilizing biofertilizers and their effect on growth of wheat (Triticum aestivum L.). Microbiol Res. 2017;20:107-17.

16. Hermosa R, Viterbo A, Chet I, Monte E. Plant-beneficial effects of Trichoderma and of its genes. Microbiology. 2012;158:17-25.

17. Nayyar A, Hamel C, Lafond G, Gossen B, Hanson K, Germida J. Soil microbial quality associated with yield reduction in continuous-pea. Appl Soil Ecol. 2009;43:115-21.

18. Ahemad M, Kibret M. Mechanisms and applications of plant growth promoting rhizobacteria: current perspective. J King Saud Univ-Sci. 2014;26:1-20.

19. Mazzola M, Manici LM. Apple replant disease: role of microbial ecology in cause and control. Annu Rev Phytopathol. 2012;50:45-65.

20. Kang Y, Shen M, Wang H, Zhao Q. A possible mechanism of action of plant growth-promoting rhizobacteria (PGPR) strain Bacillus pumilus WP8 via regulation of soil bacterial community structure. J Gen Appl Microbiol. 2013;59:267-77.

21. Bonten TLC, Zwart KB, Rietra RPJ, Postma R, de Haas MJG. Bio-slurry as fertilizer. Is bio-slurry from household digesters a better fertilizer than manure? A literature review. Wageningen, Alterra Wageningen UR; 2014.

22. Dong W, Zhao J, Zhong F, Zhu W, Jiang J, Wu S, Yang D, Li D, Quan L. Biotransformation of Panax ginseng extract of metabolites by rat intestinal microflora: identification and quantification of metabolites using liquid chromatography-tandem mass spectrometry. J Ginseng Res. 2017:41:540-7.

23. Zhao Q, Wu Y, Fan Q, Han Q, Paré PW, Xu R, Wang YQ, Wang SM, Zhang JL. Improved growth and metabolite accumulation in Codonopsis pilosula (Franch.) Nannf. by inoculation of Bacillus amyloliquefaciens GB03. J Agr Food Chem. 2016;64:8103-8.

24. Heuberger H, Bauer R, Friedl F, Heubl G, Hummelsberger J, Nögel R. Cultivation and breeding of Chinese medicinal plants in Germany. Planta Med. 2010;76:1956-62.

25. Zhang B, Peng Y, Zhang Z, Liu H, Qi Y, Liu S. GAP production of TCM herbs in China. Planta Med. 2010;76:1948-55.

26. Fierer N, Hamady M, Lauber CL, Knight R. The influence of sex, handedness, and washing on the diversity of hand surface bacteria. Proc Natl Acad Sci USA. 2008;105:17994-9.
27. Rodrigues JLM, Pellizari VH, Mueller R, Baek K, Jesus ECD, Paula FS. Conversion of the Amazon rainforest to agriculture results in biotic homogenization of soil bacterial communities. Proc Natl Acad Sci USA. 2013;110:988-93.

28. Caporaso JG, Bittinger K, Bushman FD, DeSantis TZ, Andersen GL, Knight R. PyNAST: a flexible tool for aligning sequences to a template alignment. Bioinformatics. 2010;26:266-7.

29. Wang Q, Garrity GM, Tiedje JM, Cole J. Naïve Bayesian classifier for rapid assignment of rRNA sequences into the new bacterial taxonomy. Appl Environ Microbiol. 2007;73:5261-7.

30. Abd-Elsalam KA, Aly IN, Abdel-Satar MA, Khalil MS, Verreet JA. PCR identification of Fusarium genus based on nuclear ribosomal-DNA sequence data. Afr J Biotechnol. 2013;2:82-5.

31. Rousk J, Bååth E, Brookes PC, Lauber CL, Lozupone C, Caporaso JG. Soil bacterial and fungal communities across a pH gradient in an arable soil. ISME J. 2010;4:1340-51.

32. Yu F, Bao J, Ma Q, Jin J, Ren Y, Wang X. Effects of application of three soil conditioners on yield and quality of farmland-cultured ginseng. Spec Wild Econ Animal Plant Res. 2009;2:18-20.

33. Jang IB, Lee DY, Yu J, Park HW, Mo HS, Park KC, Hyun DY, Lee EH, Kim $\mathrm{KH}$, Oh CS. Photosynthesis rates, growth, and ginsengoside contents of 2-yr-old Panax ginseng grown at different light transmission rates in a greenhouse. J Ginseng Res. 2015;39:345-53.

34. Zhang M, Li R, Cao LL, Shi JJ, Liu HJ, Huang Y, Shen Q. Algal sludge from Taihu Lake can be utilized to create novel PGPR-containing bio-organic fertilizers. J Environ Manag. 2014;132:230-6.

35. Rosenzweig N, Tiedje JM, Quensen JF, Meng Q, Hao JJ. Microbial communities associated with potato common scab-suppressive soil determined by pyrosequencing analyses. Plant Dis. 2012;96:718-25.

36. Shen ZZ, Zhong ST, Wang YG, Wang BB, Mei XL, Li R, Ruan Y, Shen Q. Induced soil microbial suppression of banana Fusarium wilt disease using compost and biofertilizers to improve yield and quality. Eur J Soil Biol. 2013;57:1-8

37. El-Haddad ME, Mustafa MI, Selim SM, El-Tayeb TS, Mahgoob AE, Aziz NH. The nematicidal effect of some bacterial biofertilizers on Meloidogyne incognita in sandy soil. Braz J Microbiol. 2011;42:105-13.

38. Whipps JM. Microbial interactions and biocontrol in the rhizosphere. J Exp Botany. 2001;52:487-511.

39. Trabelsi D, Mhamdi R. Microbial inoculants and their impact on soil microbial communities: a review. Biomed Res Int. 2013;2013:863240.

40. Li J, Huang L. Effects of biological fertilizer on the growth of Ginseng. Ginseng Res. 2009;1:38-40.

41. Guo C, Guan Z, Li Y, Yang X, Wang F. Effects of biofertilizers on soil microecological environment of ginseng replantation. Biotechnology. 2004; 14:55-6

42. Qiu MH, Zhang RF, Xue C, Zhang SS, Li SQ, Zhang N, Shen Q. Application of bio-organic fetrtilizer can control Fusarium wilt of cucumber plants by regulating microbial community of rhizosphere soil. Biol Fert Soils. 2012;48:807-16.

43. Yuan SF, Wang LL, Wu K, Shi JX, Wang MS, Yang XM, Shen Q, Shen B. Evaluation of Bacillus-fortified organic fertilizer for controlling tobacco bacterial wilt in greenhouse and field experiments. Appl Soil Ecol. 2014;75:86-94.

44. Shen Z, Ruan Y, Chao X, Zhang J, Li R, Shen Q. Rhizosphere microbial community manipulated by 2 years of consecutive biofertilizer application associated with banana Fusarium wilt disease suppression. Biol Fert Soils. 2015;51:553-62.

45. Dong L, Xu J, Niu W, Gao Y, Zhang N, Naoki F, Li X, Chen S. Effects of improving measures on soil micro-ecology and survival rate of ginseng in farmlands. China J Chin Materia Medica. 2016;41:4334-9.

46. Berendsen RL, Pieterse CMJ, Bakker PHM. The rhizosphere microbiome and plant health. Trends Plant Sci. 2012;17:478-86.

47. Zaheer A, Mirza BS, Mclean JE, Yasmin S, Shah TM, Malik K, Mirza MS. Association of plant growth-promoting Serratia spp. with the root nodules of chickpea. Res Microbiol. 2016;167:510-20.

48. Dong L, Xu J, Li Y, Fang H, Niu W, Li X, Zhang Y, Ding W, Chen S. Manipulation of microbial community in the rhizosphere alleviates the replanting issues in Panax ginseng. Soil Biol Biochem. 2018;125:64-74. 
49. Egamberdiyeva D. The effect of plant growth promoting bacteria on growth and nutrient uptake of maize in two different soils. Appl Soil Ecol. 2007;36:184-9.

50. Ahemad M, Khan MS. Plant growth promoting activities of phosphatesolubilizing Enterobacter asburiae as influenced by fungicides. Eur Asia J Biosci. 2010;4:88-95.

51. Verma JP, Yadav J, Tiwari KN, Lavakush SV. Impact of plant growth promoting rhizobacteria on crop production. Int J Agric Res. 2010;5:954-83.
52. NowakTB, Gould SJ, Kraus J, Loper JE. Production of 2, 4-diacetylphloroglucinol by the biocontrol agent Pseudomonas fluorescens Pf-5. Can J Microbiol. 1994;40:1064-6.

\section{Publisher's Note}

Springer Nature remains neutral with regard to jurisdictional claims in published maps and institutional affiliations.
Ready to submit your research? Choose BMC and benefit from:

- fast, convenient online submission

- thorough peer review by experienced researchers in your field

- rapid publication on acceptance

- support for research data, including large and complex data types

- gold Open Access which fosters wider collaboration and increased citations

- maximum visibility for your research: over $100 \mathrm{M}$ website views per year

At BMC, research is always in progress.

Learn more biomedcentral.com/submissions 